\title{
Assessing the Uptake of Supervised Delivery in the Akuapem South District in the Eastern Region of Ghana
}

\author{
Stephen Manortey*, Appiagyei Buabeng \\ Ensign College of Public Health, Kpong, Eastern Region, Ghana \\ Email: ^steve.manortey@ensign.edu.gh
}

How to cite this paper: Manortey, S. and Buabeng, A. (2020) Assessing the Uptake of Supervised Delivery in the Akuapem South District in the Eastern Region of Ghana. Open Access Library Journal, 7: e6131. https://doi.org/10.4236/oalib.1106131

Received: February 3, 2020

Accepted: March 7, 2020

Published: March 10, 2020

Copyright $\odot 2020$ by author(s) and Open Access Library Inc.

This work is licensed under the Creative Commons Attribution International License (CC BY 4.0).

http://creativecommons.org/licenses/by/4.0/ (c) (i) Open Access

\begin{abstract}
Introduction: In spite of the national target of achieving at least an $80 \%$ skilled delivery, skilled health providers attended to just $56.2 \%$ of deliveries in 2016 according to the Ghana Health Service annual report. The highest proportion of ANC registrants in the Akuapem South District in the Eastern Region of Ghana who sought skilled attendance at birth for the past 3 years has been about $36 \%$ as recorded in 2017. The fundamental factors responsible for this low skilled delivery in the district are poorly understood. The aim of this study, however, was to explore the factors that contribute to the uptake of skilled delivery in the Akuapem South District. Methodology: This cross-sectional study involved 371 women in the reproductive ages (15 - 49 years) who had delivered within the last 12 months preceding January 2019, and have been residents in the research communities during the period of pregnancy. A convenient sampling technique was used to select all 371 respondents from 15 communities. Structured questionnaires were used for the interviews by trained staff. Results: The prevalence of skilled delivery among respondents in this district as revealed by this study was $65.77 \%$ despite the 97.04\% reported ANC attendance for at least once. Significant influencers of the uptake of skilled delivery were; maternal age, mother and partner's educational level, partner's occupation, the attitude of health staff/midwives, distance to the nearest health facility, transportation fare, and availability of medical equipment in the nearest health facility. Conclusion: Even though the overall ANC attendance was high, including women who made more than three visits, uptake of supervised delivery is a major challenge. There is, therefore, the need for the Akuapem South District Health Directorate to fully strengthen the adopted WHO's goal that focuses on ANC at the individual facility levels.
\end{abstract}




\section{Subject Areas}

Public Health

\section{Keywords}

Skilled Delivery, ANC, Akuapem South District, Ghana

\section{Introduction}

Maternal health improvement attracted global attention at the 1987 Safe Motherhood Conference held in Nairobi, Kenya [1]. Since then, improving women's health issues pertaining to pregnancy and delivery has become the centerpiece of national development efforts in many developing countries including Ghana. However, despite this significant effort, maternal mortality has not as yet declined significantly in African countries as one would expect [2].

Several empirical studies on utilization of skilled delivery services have identified a number of socioeconomic, personal, physical availability and quality of health care and facilities as well as the economic cost of services, transportation and cultural beliefs of mothers as significant influencing factors. It is common knowledge that with access to a skilled birth attendant at delivery, most obstetric complications can be prevented or managed. Globally, a consensus has been reached over the past years on the interventions that are significant in reducing maternal mortality. In 2016, skilled health providers attended to $56.2 \%$ of deliveries in Ghana [3] relative to the $73.7 \%$ recorded by the 2014 Ghana Demographic and Health Survey (GDHS) [4]. Achieving the national target of $80 \%$ skilled delivery will continue to be an insurmountable challenge unless the fundamental factors responsible for the low skilled delivery are addressed [3].

Globally, coverage of skilled attendants during childbirth increased from $61 \%$ in 2000 to $78 \%$ in 2016 . However, despite steady improvement globally and within regions, millions of births were not assisted by trained health workers. The estimated coverage of births attended by skilled health personnel in 2016 shows the inequality between WHO regions, as only half of the births in the Sub-Saharan Africa (SSA) region, where maternal mortality is highest, are attended by skilled health personal. Whereas in other WHO regions over $70 \%$ to $99 \%$ of all births are attended by skilled health personnel [5]. The Ghana Health Service's 2016 annual report revealed a relatively lower than the global figure of around 78\% skilled deliveries in Ghana (56.2\%) in 2016. The figures are even worse in rural areas in the country [3].

The provision of maternal health services with sufficient quality increases the chances of women delivering under the supervision of skilled providers. The reverse can, however, produce undesirable consequences, including, for example, increases in the number of home deliveries and maternal mortalities. Maternal deaths can be prevented if women have access to quality health services so that 
complications can easily be managed [6].

Global evidence suggests a strong correlation between benefiting from antenatal care (ANC) services and positive pregnancy outcomes. Essential interventions in ANC include intermittent preventive treatment for malaria during pregnancy (IPTp), identification and management of obstetric complications such as preeclampsia, tetanus toxoid immunization, intermittent and identification and management of infections including HIV (GHS, 2016). In addition, ANC affords the opportunity to promote the utilization of skilled attendance during delivery and healthy actions such as breastfeeding, early postnatal care, and family planning. More than $80 \%$ of Ghanaian pregnant women had at least one contact with a skilled provider during pregnancy in 2016. Notwithstanding, the country has recorded declines in its antenatal coverage over the past three years [3].

Mwabu (1986), noted that the majority of patients in his Kenyan study sought health care from outside the "free" government health care systems due to the poor attitude of health care providers. Most deliveries occur in the night [7]. The availability of health staff in the night is an indispensable factor in the determination of the level of confidence that pregnant women have in a health system. Most health facilities in rural Ghana do not either have adequate accommodation for essential staff like midwives or do not have a proper schedule of work that ensures that there is always a health staff available for delivery services especially in the night.

Even though the 2011 Ghana MICS and GHS 2016 reports 67\% and 56.2\% skilled deliveries in health facilities respectively, skilled delivery has still been very low in rural areas. "Nearly nine in ten women in urban areas (88\%) deliver in a health facility, compared to 53 percent of their rural counterparts" (MICS, 2011) [8]. These findings are confirmed by the findings of Asante-Sarpong et al, (2016) which revealed; "Mothers living in urban areas are 3.79 times more likely to use skilled delivery services under the NHIS policy than those living in rural areas" [9].

The age at which a woman gives birth is noted to have a significant bearing on her decision to deliver in the hands of skilled persons in health facilities. In Ghana, the 2003 DHS showed that mothers' age was not significantly related to their delivery behavior [10]. This is however inconsistent with modern findings of the MICS (2011) which indicated that "by age, younger women 15 - 19 years are most likely to deliver in a health facility (71\%) compared with women $35-49$ (60\%)". The educational level of women is proven to have a positive relationship with major decisions concerning their health and survival. One such decision is the utilization of maternal health services with skilled personnel. The Ghana MICS (2011) revealed that women with higher levels of educational attainment are more likely to deliver in a health facility than women with no education, as, $43 \%, 79 \%$ and $94 \%$ of women with No, Middle/JSS and Secondary/Higher levels of education respectively delivered in a health facility with skilled attendants [8]. 
A study in India indicated that only 12 percent of births of illiterate women occurred in health institutions compared with 67 percent of births of women who had at least a middle school education [11].

The National Health Insurance Scheme (NHIS) has over the years increased the health-seeking behavior of most pregnant Ghanaians because of the free maternal care policy under the scheme [12]. Factors influencing the use of skilled delivery services under the NHIS free maternal care policy operate at both individual and policy implementation levels. Research findings by Asante-Sarpong et al, (2016) revealed that delivery service use under the free maternal healthcare policy is relatively low (65\%) when compared with nearly universal awareness (97.3\%) of Ghanaian pregnant women about the policy. However, "the likelihood of using delivery services under the policy is higher for mothers who are aware and has full knowledge of the total benefit package of the policy" [9].

In addition to distance, the cost of health services such as user fees and transport fares can be a major obstacle to women's use of supervised delivery health services. Mrs. Carla AbouZahr of the World Health Organization's Maternal and Newborn Health/Safe Motherhood Programme noted that: "for poorer women, imposing or raising fees almost always deters them from using services. Even when formal fees are low or nonexistent, there can be other costs that deter women from seeking care. These costs may include transport, accommodation, drugs, and supplies, as well as informal or under the table fees that may be imposed by health staff. When women lack control over resources and are dependent on others to provide funds, fees of any kind can be a serious obstacle to their use of services [13].

The availability of health infrastructure, though very key, does not alone guarantee the acceptability of delivery services by pregnant women. The location of the health facility within the community (distance to a health facility), the availability of accommodation facility for the health staff within the health facility, the availability of referral facilities to facilitate easy movement of emergency cases are all factors that tend to influence the decision for a pregnant woman to seek skilled delivery. Distance is a physical barrier to the utilization of health care [14], yet, a study by Blay (1996) in Kintampo proved that, though health facilities could be very near to the people they will not utilize it [15].

This study, therefore, aimed at evaluating the factors that influence the low uptake of supervised delivery services in selected health facilities in the Akuapem South District of the Eastern Region, Ghana

\section{Methods}

\subsection{Profile of Study Area}

The Akuapem South District, with Aburi as the capital is one of the thirty-two districts in the Eastern Region of Ghana. Until its creation in September 2012, the area formed part of the Nsawam Adoagyiri Municipality which capital is Nsawam. The District is situated in the South-Eastern part of the Region. The 
District comprises of five Sub-Districts with about 108 communities and an estimated 2018 population of 44,492 [16]. The study population included all women in their reproductive age (15 - 49 years) with a child under one-year-old who delivered and lives in the Akuapem South District in the Eastern Region of Ghana. The estimated population of such women in the District is 1,780 representing 4\% of the total 2018 estimated population. Any woman out of the reproductive age (15 - 49 years), not willing to consent to participation or psychologically unstable at the time of the study was excluded from participating in the study.

\subsection{Study Design and Sample Size}

A cross-sectional descriptive quantitative design was employed from $22^{\text {nd }}$ January to 27 th February 2019 to gather data from the study participants using structured questionnaires consisting of both open and closed-ended questions. A sample size of about 354 mothers was estimated using the Cochran formula [17] at $95 \%$ confidence interval and a 5\% margin of error, considering a non-uptake of skilled delivery prevalence rate of $64 \%$ in the district.

$$
n=\frac{z^{2} \times p(1-p)}{e^{2}}=\frac{(1.96)^{2} \times 0.64 \times 0.36}{(0.05)^{2}}=354.04
$$

where,

$n=$ the required sample size

$p=$ prevalence of problem (0.64)

$z=\mathrm{z}$-score at $95 \%$ confidence interval (1.96), and

$e=$ margin of error $(0.05)$

Adding a $10 \%$ non-response rate to the generated sample size, the operational size was brought to about 390 respondents.

\subsection{Study Variables}

The "utilization of supervised delivery among women" who have met all the inclusion criteria was considered as the dependent variable under this study. All other indicators such as the demography, psychosocial status, cultural believes and practices, economic status, and physical environment including availability and distance to health facilities were classified as explanatory variables.

\subsection{Data Collection and Management}

The study instruments and tools were pre-tested within two communities (Obosono and Abaase) with similar demographic characteristics as the studied communities with over 20 participants. The data were analyzed with STATA statistical software package (StataCorp2007. Stata Statistical Software Release 14, StataCorp LP, College Station, TX, USA). Data is presented in the form of frequency distribution tables and graphs such as pie-charts and bar graphs. Cross-tabulation, chi-square test, and regression analysis were used in present- 
ing and analyzing the association between variables and also predict the level of relationship between the dependent and independent variables. Logistic Regression was used because the response variables are binary (i.e. dichotomous) in nature. The results of logistic regression are presented in the form of estimated Odds-ratios with $p$-values at a $95 \%$ confidence interval.

\subsection{Ethical Consideration}

Ethical approval for the study was obtained from the Ethical Review Committee of Ensign College of Public Health and administrative permission was sought from the Akuapem South District Health Directorate of Ghana Health Service (GHS) at where the research was undertaken.

Informed consent forms were administered to each participant in a language she understood before the research questionnaire. Measures were instituted to ensure confidentiality of responses during and after the study such that responses could not be traceable to respondents. Responding to questions did not pose any risk to respondents.

\section{Results}

\subsection{Study Population Characteristics}

Out of the total 389 questionnaires administered, 371 were returned in satisfactory condition, resulting in a $95 \%$ study response rate. Selected variables were analyzed to provide insight into the distribution pattern of responses provided by the study participants.

About $30 \%$ of the respondents forming the majority were aged between 25 and 29 years. This distribution shows that there were at least enough women in all the reproductive age group categories to be able to do a good comparison. Out of the total 371 respondents, 134 (36.12\%) were married, while the remaining $237(63.88 \%)$ were single. A greater proportion of respondents $(57.68 \%)$ were Akan, $25.34 \%$ were Ewe with $12.67 \%$ and $4.31 \%$ of them having $\mathrm{Ga} /$ Adangme and other minority ethnic background respectively.

In relation to employment, 205 (55.26\%) of the mothers interviewed were self-employed, 26 (7.01\%) and 45 (12.13\%) worked for Government and Private Companies respectively, 30 (8.09\%) were farmers while 65 (17.52\%) were unemployed. However, only $3.23 \%$ of the partners of the women interviewed were unemployed with $8.89 \%$ and $47.17 \%$ working for Government and Private Companies respectively while $6.47 \%$ with $34.23 \%$ were self-employed and farmers respectively.

The distribution of the educational background of the respondents revealed that only $4.31 \%$ of the women had no formal education. The majority $(53.1 \%)$ of the partners of the respondents had Middle/JHS education with 6.47\%, 22.1\% and $15.9 \%$ having Primary, Secondary and Tertiary level education respectively. Only $2.43 \%$ of the partners had no formal education (Table 1 ). 
Table 1. Background characteristics of respondents.

\begin{tabular}{|c|c|c|}
\hline Variable & Frequency & Percentage \\
\hline \multicolumn{3}{|l|}{ Age Group } \\
\hline Below 20 years & 54 & 14.56 \\
\hline 21 to 24 & 54 & 14.56 \\
\hline $25-29$ & 112 & 30.19 \\
\hline $30-34$ & 92 & 24.8 \\
\hline $35+$ & 59 & 15.9 \\
\hline \multicolumn{3}{|l|}{ Educational Level } \\
\hline No education & 16 & 4.31 \\
\hline Primary & 59 & 15.9 \\
\hline Middle/JHS & 217 & 58.49 \\
\hline Secondary/Tech./Voc & 54 & 14.56 \\
\hline Tertiary & 25 & 6.74 \\
\hline \multicolumn{3}{|l|}{ Partners' Educational level } \\
\hline No education & 9 & 2.43 \\
\hline Primary & 24 & 6.47 \\
\hline Middle/JHS & 197 & 53.1 \\
\hline Secondary/Tech./Voc & 82 & 22.1 \\
\hline Tertiary & 59 & 15.9 \\
\hline \multicolumn{3}{|l|}{ Marital Status } \\
\hline Single & 237 & 63.88 \\
\hline Married & 134 & 36.12 \\
\hline \multicolumn{3}{|l|}{ Ethnicity } \\
\hline Akan & 214 & 57.68 \\
\hline Ga/Adangme & 47 & 12.67 \\
\hline Ewe & 94 & 25.34 \\
\hline Others & 16 & 4.31 \\
\hline \multicolumn{3}{|l|}{ Occupation } \\
\hline Government Worker & 26 & 7.01 \\
\hline Private Company Worker & 45 & 12.13 \\
\hline Self Employed & 205 & 55.26 \\
\hline Farmer & 30 & 8.09 \\
\hline Unemployed & 65 & 17.52 \\
\hline \multicolumn{3}{|l|}{ Partners' Occupation } \\
\hline Government Worker & 33 & 8.89 \\
\hline Private Company Worker & 175 & 47.17 \\
\hline Self Employed & 24 & 6.47 \\
\hline Farmer & 127 & 34.23 \\
\hline Unemployed & 12 & 3.23 \\
\hline
\end{tabular}




\subsection{Influence of Socio-Demographic Characteristics on Uptake of Supervised Delivery}

Table 2 illustrates the level of association between selected socio-demographic characteristics of the respondents on the uptake of supervised delivery. Out of the 371 respondents, 244 (65.77\%) underwent supervised/skilled delivery during the birth of their last child while the remaining 127 (34.23\%) did not use skilled delivery during the birth of their last child.

The woman's age, educational level, and the partner's educational level are all statistically significant predictors of the use of skilled delivery with the associated $p$-values of $p=0.021, p=0.001$, and $p=0.045$ respectively. Respondents' partner's occupation was also statistically significant predictor of the use of skilled delivery with a chi-square $p$-value of $p=0.02$. However, the respondents' professed religious faith, marital status, ethnicity, and occupation showed no statistical influence on the use of skilled delivery, $(p=0.07, p=0.069, p=0.923$, and $p$ $=0.213)$.

\subsection{Influence of Predictor Variables on Uptake of Supervised Delivery}

Neither ANC attendance nor the frequency of attendance showed any significant statistical association with respondents' decision to seek skilled delivery at their last birth ( $p=0.521, p=0.184$ respectively). $96.06 \%$ of respondents who used unskilled delivery at their last birth had attended ANC at least once while $2.46 \%$ of women who used skilled delivery had not done any ANC visit prior to their last delivery. Even though $90.98 \%$ of respondents who had done three ANC visits accessed skilled delivery, more than $84.25 \%$ of women who used unskilled delivery had also done 3 ANC visits prior to their last delivery.

The person(s) who accompany a woman to the delivery site has a significant influence on the decision to access skilled delivery $(p=<0.001)$. A greater proportion of women who used skilled delivery at birth (99) were accompanied to the delivery site by their partners. $37.8 \%$ of women who used unskilled delivery were accompanied to the delivery site by persons other than their partners, in-laws, parents or siblings. The number of wives a partner had in addition to respondents showed no relationship with their decision to seek skilled delivery $(p=0.258)$.

Respondents' perception of the attitude of midwives showed a statistical relationship with a woman's decision to seek skilled delivery $(p=<0.001)$. Out of the 371 respondents, $119(32.10 \%)$ perceived the attitude of midwives towards women to be very friendly, while $27(7.28 \%)$ and $9(2.43 \%)$ perceived midwives as unfriendly and very unfriendly respectively. Out of the women who accessed unskilled delivery, $27.56 \%$ perceived the attitude of midwives to be very friendly, while $34.43 \%$ of the women who used skilled delivery at their last birth perceived the attitude of midwives to be very friendly.

Out of the 127 respondents who used unskilled delivery, the nearest health 
Table 2. Bivariate analysis of socio-demographic factors' influence on the uptake of supervised delivery service.

\begin{tabular}{|c|c|c|c|c|c|}
\hline \multirow[t]{3}{*}{ Variables } & \multicolumn{4}{|c|}{ Delivery } & \multirow{3}{*}{$p$-value } \\
\hline & \multicolumn{2}{|c|}{ Unskilled } & \multicolumn{2}{|c|}{ Skilled } & \\
\hline & $\mathbf{n}$ & $\%$ & $\mathbf{n}$ & $\%$ & \\
\hline Overall Prevalence & 127 & 34.23 & 244 & 65.77 & \\
\hline Age Group & & & & & \multirow{6}{*}{0.021} \\
\hline Below 20 years & 27 & 21.26 & 27 & 11.07 & \\
\hline $20-24$ & 24 & 18.9 & 30 & 12.3 & \\
\hline $25-29$ & 33 & 25.98 & 79 & 32.38 & \\
\hline $30-34$ & 27 & 21.26 & 65 & 26.64 & \\
\hline $35+$ & 16 & 12.6 & 43 & 17.62 & \\
\hline \multicolumn{6}{|l|}{ Educational Level } \\
\hline No education & 11 & 8.66 & 5 & 2.05 & \multirow{5}{*}{$<0.001$} \\
\hline Primary & 21 & 16.54 & 38 & 15.57 & \\
\hline Middle/JHS & 80 & 62.99 & 137 & 56.15 & \\
\hline Secondary/Tech./Voc & 9 & 7.09 & 45 & 18.44 & \\
\hline Tertiary & 6 & 4.72 & 19 & 7.79 & \\
\hline \multicolumn{6}{|l|}{ Partner's Educational Level } \\
\hline No education & 4 & 3.15 & 5 & 2.05 & \multirow{5}{*}{0.045} \\
\hline Primary & 13 & 10.24 & 11 & 4.51 & \\
\hline Middle/JHS & 72 & 56.69 & 125 & 51.23 & \\
\hline Secondary/Tech./Voc & 25 & 19.69 & 57 & 23.36 & \\
\hline Tertiary & 13 & 10.24 & 56 & 22.95 & \\
\hline \multicolumn{6}{|l|}{ Religion } \\
\hline Traditional religion & 1 & 0.79 & 1 & 0.41 & \multirow{5}{*}{0.07} \\
\hline Roman Catholic & 10 & 7.87 & 8 & 3.28 & \\
\hline Protestants & 104 & 81.89 & 220 & 90.16 & \\
\hline Moslem & 9 & 7.09 & 14 & 5.74 & \\
\hline Atheist & 3 & 2.36 & 1 & 0.41 & \\
\hline \multicolumn{6}{|l|}{ Marital } \\
\hline Single & 73 & 57.48 & 164 & 67.21 & \multirow[t]{2}{*}{0.069} \\
\hline Married & 54 & 42.52 & 80 & 32.79 & \\
\hline \multicolumn{6}{|l|}{ Ethnicity } \\
\hline Akan & 74 & 58.27 & 140 & 57.38 & \multirow{4}{*}{0.923} \\
\hline Ga/Adangme & 16 & 12.60 & 31 & 12.70 & \\
\hline Ewe & 33 & 25.98 & 61 & 25.00 & \\
\hline Others & 4 & 3.15 & 12 & 4.92 & \\
\hline
\end{tabular}




\section{Continued}

\begin{tabular}{cccccc}
\hline Occupation & & & & & \\
Unemployed & 21 & 16.54 & 44 & 18.03 & \\
Government Worker & 4 & 3.15 & 22 & 9.02 & $\mathbf{0 . 2 1 3}$ \\
Private Company Worker & 15 & 11.81 & 30 & 12.30 & \\
Self Employed & 74 & 58.27 & 131 & 53.69 & \\
Farmer & 13 & 10.24 & 17 & 6.97 & \\
Partners' Occupation & & & & & \\
Unemployed & 5 & 3.94 & 7 & 2.87 & \\
Government Worker & 8 & 6.30 & 25 & 10.25 & \\
Private Company Worker & 48 & 37.80 & 127 & 52.05 & \\
Self Employed & 11 & 8.66 & 13 & 5.33 & \\
Farmer & 55 & 43.31 & 72 & 29.51 & \\
\hline
\end{tabular}

facility where they could have accessed skilled delivery was less than 30 mins walk for 81 respondents (63.78\%), and more than an hour's walk for 8 respondents (6.30\%). Relatively, of the 244 respondents who used skilled attendance at birth, the nearest health facility where they accessed skilled delivery was less than 30mins walk for 178 (72.95\%), and more than an hour's walk for 15 (6.15\%). Distance to the nearest health facility where a woman could access skilled delivery services was statistically significant $(p=0.002)$ influencer of the use of skilled delivery among mothers.

The availability of standard medical equipment that supports quality skilled delivery is a variable that influences a woman's decision to seek skilled attendance at birth $(p=0.016)$. Out of the total of 173 respondents who perceived equipment to be adequately available in their nearest health facility, 120 (69.36\%) accessed skilled delivery while 53 (30.64\%) accessed unskilled attendance at birth. However, $11.81 \%$ of respondents who accessed unskilled delivery perceived equipment to be very inadequate relative to the $8.61 \%$ of respondents who accessed skilled delivery.

Out of the 371 respondents, 171 (46.09\%) received some form of traditional treatment before or after the birth of their last child while 200 (53.91) did not receive any cultural treatment. The cultural treatments received at birth did not statistically influence skilled delivery $(p=0.913)$.

Respondents opinion on transport fares in the community statistically influences skilled delivery $(p=<0.001)$. A greater proportion of respondents who used unskilled delivery 66 (51.97\%) perceived transport fares as affordable while $25.2 \%$ claimed it is not affordable. $22.83 \%$ of respondents were indifferent to the transport fares. Out of the 244 respondents who used skilled attendance at birth, $155(63.52 \%), 75(30.74 \%)$ and $14(5.74 \%)$ perceived transport fares as affordable, not affordable and indifferent respectively.

Payment made during delivery is statistically not an influencer of the decision 
to seek skilled attendance at birth $(p=0.083)$. Household income also did not influence skilled delivery $(p=0.064)$ (Table 3$)$.

\subsection{Multivariate Logistic Regression Model for Relevant Demographic Variables}

All the age groups of the respondents (except 20 - 24 years) were significant factors ( $p=0.011, p=0.014, p=0.013)$ that influenced the uptake of skilled delivery with reference to the age group "below 20 years". After adjusting for confounding factors, respondents in the 20 - 24 age group were 1.29 times more likely to deliver with skilled supervised attendants with reference to those below 20 years age range. Respondents in the age group 25 - 29 years, 30 - 34 years and above 35 years were 3.33 times, 4.15 times and 5.02 times (respectively) more likely to deliver with skilled attendants with reference to the below 20 years age group.

Before adjusting, all levels of education of respondents were statistically related to skilled delivery (with their p-values less than 0.05 ) with reference to no education. However, the adjusted figures show that all the levels of education statistically influence skilled delivery with reference to no education except tertiary level education $(p=0.062)$.

Marriage was statistically not a significant influencer $(p=0.065)$ of skilled delivery with reference to single women before adjustment. After adjustment, marriage with a Chi-square p-value of 0.005 is indicative of an association with skilled delivery. Before adjustment, married women were 0.34 times less likely to access supervised delivery with reference to single women but after adjustment, married women were 0.52 times less likely to seek supervised delivery with reference to single women.

With reference to the unemployed, none of the partners' occupation status is a statistically significant factor that influences a woman's decision to seek skilled delivery, before and after adjustment. However, women whose partners worked for the government were 2.23 times and 1.12 times more likely to access skilled delivery with reference to women whose partners were unemployed, before and after adjustment respectively. After adjusting, women whose partners either worked for private companies, self-employed or farmers were 1.08 times more likely, 0.5 times less likely and 0.44 times less likely to access skilled delivery with reference to women whose partners were unemployed (Table 4).

\subsection{Multivariate Logistic Regression Model for Relevant Predictor Variables}

Table 5 shows the chi-square p-values, unadjusted and adjusted odds ratio from logistic regression model for statistically relevant predictor variables from the chi-square test.

Respondents who attended ANC at least once had a 1.88 times likelihood of using supervised delivery with reference to respondents who did not attend 
Table 3. Bivariate analysis between selectedvariables and the uptake of supervised delivery services.

\begin{tabular}{|c|c|c|c|c|c|}
\hline \multirow{3}{*}{ Variable } & \multicolumn{4}{|c|}{ Delivery } & \multirow{3}{*}{$p$-value } \\
\hline & \multicolumn{2}{|c|}{ Unskilled } & \multicolumn{2}{|c|}{ Skilled } & \\
\hline & $\mathrm{n}=127$ & $34.23 \%$ & $\mathrm{n}=244$ & $65.77 \%$ & \\
\hline \multicolumn{6}{|l|}{ Attendance to ANC } \\
\hline Yes & 122 & 96.06 & 238 & 97.54 & 0.521 \\
\hline No & 5 & 3.94 & 6 & 2.46 & \\
\hline \multicolumn{6}{|l|}{ Number of times ANC } \\
\hline None & 5 & 3.94 & 6 & 2.46 & \\
\hline One & 8 & 6.30 & 6 & 2.46 & 0.184 \\
\hline Two & 7 & 5.51 & 10 & 4.10 & \\
\hline Three & 107 & 84.25 & 222 & 90.98 & \\
\hline \multicolumn{6}{|l|}{ Accompanied to birth by } \\
\hline Husband/Partner & 31 & 24.41 & 99 & 40.57 & \\
\hline Father-in-law & 3 & 2.36 & 6 & 2.46 & \\
\hline Mother-in-law & 8 & 6.30 & 10 & 4.10 & $<0.001$ \\
\hline Mother & 25 & 19.69 & 50 & 20.49 & \\
\hline Sister & 12 & 9.45 & 52 & 21.31 & \\
\hline Other & 48 & 37.80 & 27 & 11.07 & \\
\hline \multicolumn{6}{|l|}{ Perception of Midwives } \\
\hline Very Friendly & 35 & 27.56 & 84 & 34.43 & \\
\hline Friendly & 46 & 36.22 & 135 & 55.33 & $<0.001$ \\
\hline Not sure/Don’t Know & 28 & 22.05 & 7 & 2.87 & \\
\hline Unfriendly & 12 & 9.45 & 15 & 6.15 & \\
\hline Very unfriendly & 6 & 4.72 & 3 & 1.23 & \\
\hline \multicolumn{6}{|l|}{ Partner having other wives } \\
\hline Yes & 5 & 3.94 & 18 & 7.38 & 0.258 \\
\hline No & 122 & 96.06 & 226 & 92.62 & \\
\hline \multicolumn{6}{|l|}{ Distance to facility } \\
\hline Less than 30 mins walk & 81 & 63.78 & 178 & 72.95 & \\
\hline About 30 mins walk & 15 & 11.81 & 38 & 15.57 & 0.002 \\
\hline 1-hour walk & 23 & 18.11 & 13 & 5.33 & \\
\hline More than 1-hour walk & 8 & 6.30 & 15 & 6.15 & \\
\hline
\end{tabular}




\section{Continued}

\section{Transport Availability}

Not always available

Sometimes Available

Always Available

Other

Available Equipment

Not Adequate

Very inadequate

Adequate

Very adequate

Don't Know

\section{Delivery Charges}

Absolutely free

Partially free

Affordable

$$
\text { Costly }
$$

Very costly

\section{Opinion on Transport fares}

Affordable
Not affordable

Can't tell/Not Sure

\section{House Income}

Regular
Not regular
Sufficient

Household decision

Woman Herself
Husband-in-law
Father-in-law
Mother-in-law
Other family member
My pastor
Other

\section{Traditional Treatment}

$\begin{array}{cccc}45 & 35.43 & 56 & 22.95 \\ 25 & 19.69 & 52 & 21.31 \\ 52 & 40.94 & 128 & 52.46 \\ 5 & 3.94 & 8 & 3.28\end{array}$

\subsection{3}

.28

$\begin{array}{llll}25 & 19.69 & 59 & 24.18\end{array}$

11.81

21

24.18 
Table 4. Multivariate Logistic Regression model for relevant demographic variables table.

\begin{tabular}{|c|c|c|c|c|c|c|}
\hline Variable & $\begin{array}{l}\text { Unadjusted } \\
\text { Odds ratio }\end{array}$ & $p$-value & $95 \%$ CI & $\begin{array}{l}\text { Adjusted } \\
\text { Odds ratio }\end{array}$ & $p$-value & $95 \% \mathrm{CI}$ \\
\hline \multicolumn{7}{|l|}{ Age Group } \\
\hline Below 20 years & 1 & & & 1 & & \\
\hline $20-24$ & 1.25 & 0.563 & $0.59-2.66$ & 1.29 & 0.551 & $0.56-3.00$ \\
\hline $25-29$ & 2.39 & 0.011 & $1.22-4.68$ & 3.33 & 0.002 & $1.53-7.22$ \\
\hline $30-34$ & 2.41 & 0.014 & $1.20-4.83$ & 4.15 & $<0.001$ & $1.80-9.57$ \\
\hline $35+$ & 2.69 & 0.013 & $1.23-5.88$ & 5.02 & $<0.001$ & $2.01-12.49$ \\
\hline \multicolumn{7}{|l|}{ Educational Level } \\
\hline No education & 1 & & & 1 & & \\
\hline Primary & 3.98 & 0.022 & $1.22-13.01$ & 3.70 & 0.037 & $1.08-12.26$ \\
\hline Middle/JHS & 3.77 & 0.017 & $1.26-11.23$ & 4.17 & 0.015 & $1.33-13.15$ \\
\hline Secondary/JSS & 11.00 & $<0.001$ & $3.07-39.43$ & 11.31 & $<0.001$ & $2.90-44.06$ \\
\hline Tertiary & 6.97 & 0.007 & $1.72-28.25$ & 4.20 & 0.062 & $0.93-18.99$ \\
\hline \multicolumn{7}{|l|}{ Marital Status } \\
\hline Single & 1 & & & 1 & & \\
\hline Married & 0.66 & 0.065 & $0.42-1.03$ & 0.48 & 0.005 & $0.28-0.80$ \\
\hline \multicolumn{7}{|c|}{ Partners' Occupation } \\
\hline Unemployed & 1 & & & 1 & & \\
\hline Gov't Worker & 2.23 & 0.26 & $0.55-9.02$ & 1.12 & 0.889 & $0.23-5.34$ \\
\hline Private & 1.89 & 0.296 & $0.57-6.24$ & 1.08 & 0.908 & $0.28-4.12$ \\
\hline Self Employed & 0.84 & 0.813 & $0.21-3.43$ & 0.50 & 0.377 & $0.10-2.35$ \\
\hline Farmer & 0.94 & 0.913 & $0.28-3.10$ & 0.56 & 0.397 & $0.15-2.14$ \\
\hline
\end{tabular}

Table 5. Multivariate logistic regression model for relevant predictor variables.

\begin{tabular}{|c|c|c|c|c|c|c|}
\hline Variable & $\begin{array}{l}\text { Unadjusted } \\
\text { Odds ratio }\end{array}$ & $p$-value & $95 \% \mathrm{CI}$ & $\begin{array}{l}\text { Adjusted } \\
\text { Odds ratio }\end{array}$ & $p$-value & $95 \% \mathrm{CI}$ \\
\hline \multicolumn{7}{|l|}{ ANC Attendance } \\
\hline No & 1 & & & 1 & & \\
\hline Yes & 1.63 & 0.43 & $0.49-5.43$ & 1.89 & 0.44 & $0.38-9.47$ \\
\hline \multicolumn{7}{|c|}{ Accompanied to birth } \\
\hline Husband/Partner & 1 & & & 1 & & \\
\hline Father-in-law & 0.63 & 0.525 & $0.15-2.65$ & 0.66 & 0.625 & $0.12-3.51$ \\
\hline Mother-in-law & 0.39 & 0.070 & $0.14-1.08$ & 0.36 & 0.123 & $0.10-1.32$ \\
\hline Mother & 0.63 & 0.144 & $0.33-1.17$ & 0.58 & 0.167 & $0.27-1.26$ \\
\hline Sister & 1.36 & 0.423 & $0.64-2.86$ & 0.95 & 0.899 & $0.40-2.22$ \\
\hline Other & 0.18 & $<0.001$ & $0.09-0.33$ & 0.17 & $<0.001$ & $0.08-0.38$ \\
\hline
\end{tabular}




\section{Continued}

Perception of Midwives

Very Friendly

Friendly

Not sure/Don't Know

Unfriendly

Very unfriendly

Distance to facility

Less than 30mins walk

About 30 min walk

1-hour walk

More than 1-hour walk

\section{Available Equipment}

Not Adequate

Very inadequate

$$
\text { Adequate }
$$

Very adequate

Don't Know

\section{Delivery Charges}

Absolutely free

Partially free

Affordable

Costly

Very costly

Opinion on Transport fares

Affordable
Not affordable
Can't tell/Not Sure

\section{Household Income}

$$
\text { Regular }
$$

Not regular

Sufficient

Not sufficient
Ref

1.22

0.10

0.52

0.21

Ref

1.15

0.26

0.85

1

0.59

0.96

1.53

0.38

1

2.03

2.60

2.88

2.81

1

1.00

0.21

1

0.57

0.45

0.44
0.206

0.011

0.011

0.013

0.207

0.450

0.007

$0.19-0.77$

$0.26-1.33$

$0.54-1.69$

0.68

1.23

1.09

0.61

1

$0.68-6.10 \quad 2.33$

$1.24-5.42$

2.10

$1.27-6.54$

$1.25-6.35$

3.29

5.98

1

0.994

$0.60-1.65$

$<0.001$

$0.10-0.41$

0.96

0.37

1

0.087

$0.29-1.09$

1.19

$0.20-1.00$

0.49

$0.22-0.88$

0.92

0.021

0.911

0.032

$0.51-1.84$

$0.15-0.92$ 
ANC. ANC attendance in itself is not a statistical factor that influences the uptake of supervised delivery $(p=0.44)$. The influence of the number of times a respondent attended ANC has not been discussed because of issues of collinearity.

The person who accompanies a woman in labour to the delivery site is a factor that influences the uptake of skilled delivery, especially if the person is not a direct family member (others). This variable has a $p$-value of $<0.001$. Women accompanied by such people are 0.83 times less likely to access supervised delivery with reference to women accompanied by their partner/husband.

Women who walk for about 1 hour before reaching a health care facility to receive skilled attendance at birth are 0.35 times less likely to seek skilled delivery with reference to respondents who walk for less than 30 minutes before reaching the nearest health facility.

Respondents who had knowledge of the availability of adequate medical equipment in the nearest health facility to support skilled attendance at birth were 1.22 times more likely to deliver with skilled attendants with reference to women who did not have adequate information on equipment availability. Delivery related costs are very significant factors that influence the uptake of skilled delivery with costly charges and very costly charges having adjusted $p$-values of $p=0.039$ and $p=0.007$ respectively. The decision to seek skilled delivery is 5.97 times affected by very costly delivery-related charges with reference to no delivery charges. The household income of respondents is a factor that proved to influence skilled delivery uptake with insufficient household income having unadjusted $p=0.021$. However, upon adjustment, household income is not statistically associated with the decision to uptake skilled delivery.

\subsection{Perception of Respondents about Attitudes of Midwives and Health Service Providers}

Figure 1 shows the perception respondents had about health staff at the health facilities and this was categorized into very friendly, friendly, Unfriendly, Very Unfriendly and Not sure/Don't know. The study showed that 181 (48.79\%) out of the total respondents had the perception that health workers are friendly with $9(2.43 \%)$ respondents having the perception that health workers are very unfriendly.

\subsection{Delivery Related Costs at Health Facilities}

Figure 2 shows delivery-related costs at health facilities. This is to measure whether delivery charges are absolutely free, partially free, affordable, costly or very costly. The study showed that $160(43.13 \%)$ respondents attested to the fact that delivery charges or costs at the facility were affordable for them while 21 (5.66\%) out of the total respondents responded that charges were partially free. Meanwhile, 78 (21.02\%) and 76 (20.49) respondents attested to it that delivery charges were very costly and costly for them respectively. 


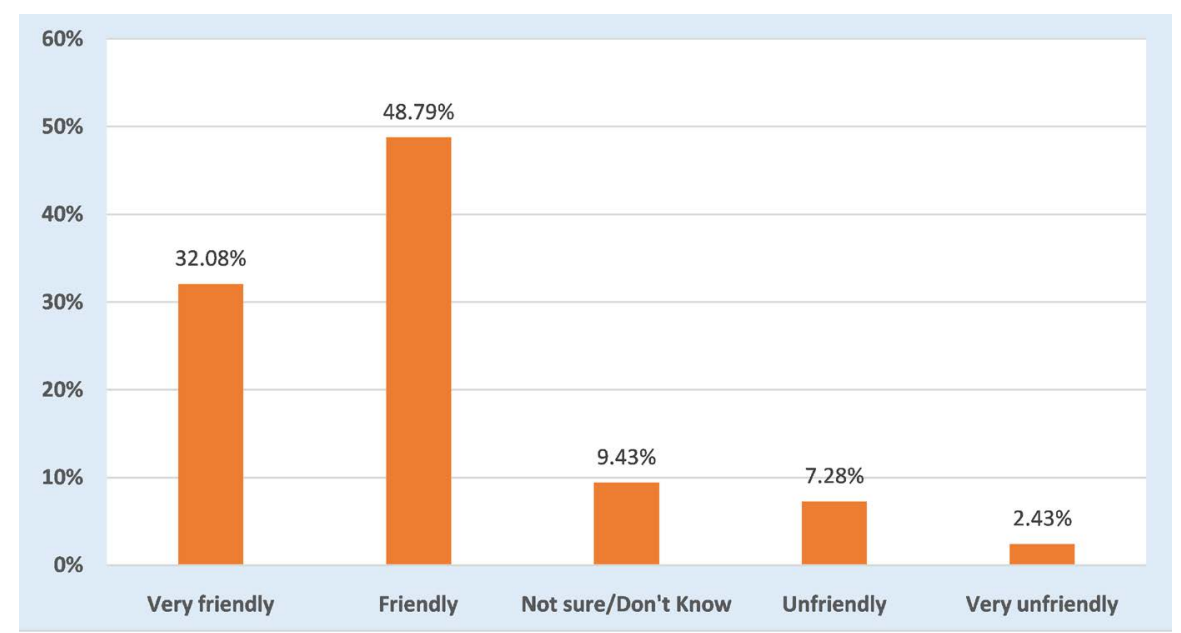

Figure 1. Respondents' perception of the attitude of health staff.

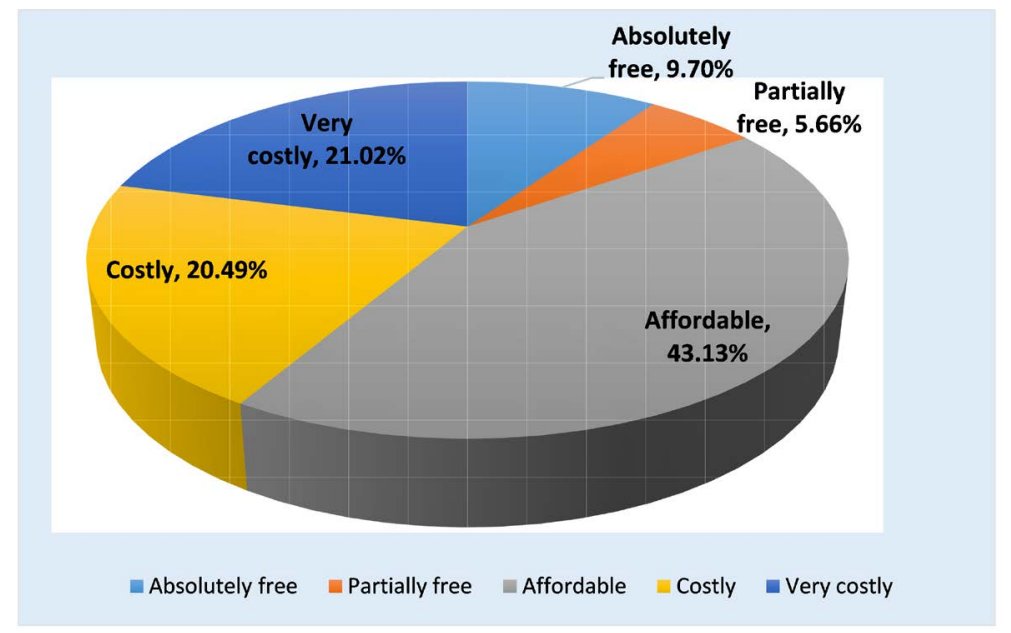

Figure 2. Delivery related cost at the health facility.

\section{Discussion}

A little over a third $(36.12 \%)$ of the participants reported being married at the time of the study, with the majority admitting being single. This observation, however, did not in anyway align with findings from an earlier study by Gudu et al., (2017) that reported as many as 8 out of every 10 women interviewed reporting married at the time of the survey [18].

The distribution of the educational background of the respondents revealed that the highest attained level of education for most women and their spouses at the time of participation was Middle/JHS. This in-context could explain the low level of appreciation for the benefits associated with the utilization of skilled delivery. The MICS 2011 report affirmed the notion that women with higher levels of educational attainment are more likely to deliver in a health facility than women with no education [8]. Also, a study by Ogbo et al. (2019) attests to the fact that participants' partners' educational level was directly related to their uptake of supervised delivery [19]. 
Despite the slight upward adjustment in the prevalence of skilled delivery in this district as revealed by this study from the 2016 reported figure of $56.2 \%$ to the current findings of $65.7 \%$, it needs mentioning that this is still below the $80 \%$ skilled delivery target of Ghana Health Service [3] and all efforts must be put in place encourage expecting mothers to use the health system for the safe delivery of their children.

The study findings revealed that the woman's age is statistically significant predictors of the use of skilled delivery. The adjusted odds of the utilization of skilled delivery were found to increase progressively as the woman's' age increases. Thus, women aged 35 years and above were found to have a five-time likelihood to use the services of a skilled health worker compared to their younger counterparts below 20 years. This confirmed other studies that found women's age as a significant predictor of the use or uptake of skilled delivery [11] [20]. It, however, contradicts 2003 DHS which showed that mothers' age was not significantly related to their delivery behavior [13].

Respondents' perception of the attitude of midwives showed a statistical relationship with a decision to seek skilled delivery. About half of the respondents (48.79\%) perceived the attitude of midwives towards women to be friendly, while whilst the rest feel otherwise. A study by Mwabu (1986) conducted in Kenya alluded to the premise that the majority of the patients sought health care from outside the "free" government health care systems due to the poor attitude of health care providers [7]. This, therefore, call for the need to improve the health worker-clientele relationship so as to encourage more pregnant mothers to avail themselves for proper medical attention.

Even though $90.98 \%$ of respondents who had done three ANC visits accessed skilled delivery, $84.25 \%$ of women who used unskilled delivery had also done three ANC visits prior to their last delivery. This result shows that the number of times a woman attend ANC does not automatically mean she will seek skilled delivery. Most of these women confessed that they go for ANC so that they can either access the "free' NHIS cards, know their Expected Date of Delivery (EDD) or know the sex of their babies. Several studies showed a significant positive linear relationship between the number of antenatal attendance and the mother's choice of delivery place [8] but this study has not discussed it because of collinearity with other study variables.

Distance to the nearest health facility where a woman could access skilled delivery services was noted in this study to be a statistically significant influencer of the use of skilled delivery among mothers. Women who walk for about 1hour before reaching a health care facility to receive skilled attendance at birth were less likely to seek skilled delivery with reference to respondents who walk for less than 30minutes before reaching the nearest health facility. This result confirms that, though health facilities could be very near to the people they will not utilize it [15]. This indicates that physical availability and proximity, though desirable, is not an end in itself but has to be complemented by other factors. 
Out of the total respondents who used skilled attendance at birth, 155 $(63.52 \%)$ perceived transport fares as affordable. These costs in some discussions were lumped to include 'under the table monies' collected by midwives during birth. This result confirms the assertion by Mrs. Carla AbouZahr of the World Health Organization's Maternal and Newborn Health/Safe Motherhood Programme that: "for poorer women, imposing or raising fees almost always deters them from using services, and that when women lack control over resources and are dependent on others to provide funds, fees of any kind can be a serious obstacle to their use of services [13] [21]. It, therefore, emphasizes the need to set systems in place that will help check the unprofessionalism of few health workers whose actions rather deter the very clients whose lives they are trained to protect.

\section{Conclusions}

Despite the high reported ANC attendance rate, the uptake of skilled delivery is far below the set national target of $80 \%$. The respondent's age, level of education attained, occupation of the partner, perception of the friendliness of the attending midwife, perception of availability of medical equipment, those accompany her to the hospital, distance and travel cost to health facility were observed to have a very significant statistical association with utilization of skilled delivery.

Alongside the national policy of having free delivery services for all expecting mothers in Ghana, conscious efforts in terms of continuing education must be offered at the least opportunity to all women in their reproductive ages so as to constantly remind them of the benefits of using skill delivery. This should include the use of antenatal attendance an entry point for a number of other health services for expectant mothers, thereby, encouraging an all-inclusive service delivery in order to scale up supervised delivery coverage in the district.

\section{Authors' Contributions}

This work was carried out in collaboration between all authors. AB and SM participated in conceiving the study and in the development of data collection tools. $\mathrm{AB}$ carried out data collection. SM and $\mathrm{AB}$ participated in the data analysis and drafting of the manuscript. All authors read and approved the final manuscript.

\section{Conflict of Interest}

All authors declare no conflict of interest.

\section{References}

[1] Safe Motherhood Initiative. https://www.ncbi.nlm.nih.gov/pubmed/12317829

[2] Cham, M., Sundby, J. and Vangen, S. (2005) Maternal Mortality in Rural Gambia: A Qualitative Study on Access to Emergency Obstetric Care. Reproductive Health, 2, 1-8. https://doi.org/10.1186/1742-4755-2-3

[3] Ghana Health Service (2016) Annual Report. 
https://www.ghanahealthservice.org/downloads/GHS_ANNUAL_REPORT_2016_n .pdf

[4] Ghana Statistical Service (2014) The Ghana Demographic and Health Survey 2014. https://dhsprogram.com/pubs/pdf/FR307/FR307.pdf

[5] Saifuddin, A., Swati, S., Nicole, W. and Kaveri, M. (2019) The Impact of a Nurse Mentoring Program on the Quality of Labour and Delivery Care at Primary Health Care Facilities in Bihar, India. BMJ Global Health, 4, e001767. https://doi.org/10.1136/bmjgh-2019-001767

[6] Thaddeus, S. and Maine, D. (1994)Too Far to Walk: Maternal Mortality in Context. Social Science \& Medicine, 38, 1091-110. https://doi.org/10.1016/0277-9536(94)90226-7

[7] Mwabu, G.M. (1986) Health Care Decisions at the Household Level: Results of a Rural Health Survey in Kenya. Social Science \& Medicine, 22, 315-319. https://doi.org/10.1016/0277-9536(86)90129-2

[8] Ghana Statistical Service (2011) Multiple Indicator Cluster Survey of Ghana (MICS, 2011). http://www2.statsghana.gov.gh/nada/index.php/catalog/52

[9] Asante-Sarpong, H., Owusu, A.Y., Saravanan, S., Appiah, E. and Abu, M. (2016) Determinants of Use of Supervised Delivery Care under Ghana's Fee Exemption Policy for Maternal Healthcare: The Case of the Central Region. BMC Pregnancy and Childbirth, 16, 172. https://doi.org/10.1186/s12884-016-0960-6

[10] Ghana Demographic and Health Survey (2003) https://www.dhsprogram.com/pubs/pdf/FR152/FR152.pdf

[11] Pavalavalli, G. and Ramesh, B.M. (1997) Maternal Education and the Utilization of Maternal and Child Health Services in India. National Family Health Survey Subject Reports.

https://scholarspace.manoa.hawaii.edu/bitstream/10125/3472/1/NFHSsubjrpt005.p df

[12] NHIS Annual Report (2012) http://www.nhis.gov.gh/files/2012\%20NHIA\%20ANNUAL\%20REPORT.pdf

[13] World Health Organization. Regional Office for the Western Pacific (2002)`National Safe Motherhood Action Plan 2001-2005: Western Pacific Region. WHO Regional Office for the Western Pacific, Manila. https://apps.who.int/iris/handle/10665/206786

[14] Buor, D. (2002) Distance as a Predominant Factor in the Utilization of Health Services in the Kumasi Metropolis, Ghana. GeoJournal, 56, 145-157. https://www.jstor.org/stable/41147677 https://doi.org/10.1023/A:1022452311911

[15] Blay, D. (1996) Service Utilization at the Kintampo Health Centre: Implication for Policy Formulation. http://197.255.68.203/handle/123456789/6058

[16] Akwapim South District (2010) http://www2.statsghana.gov.gh/docfiles/2010_District_Report/Eastern/AKWAPIM \%20SOUTH.pdf

[17] Cochran, W.G. (1977) Sampling Techniques. 3rd Edition, Wiley, New York, 428 p. https://hwbdocuments.env.nm.gov/Los\%20Alamos\%20National\%20Labs/General/1 4447.pdf

[18] Gudu, W. and Addo, B. (2017) Factors Associated with Utilization of Skilled Service Delivery among Women in Rural Northern Ghana: A Cross-Sectional Study. BMC Pregnancy Childbirth, 17, 159. https://doi.org/10.1186/s12884-017-1344-2 
[19] Ogbo, F., Dhami, M. and Ude, E. (2019) Enablers and Barriers to the Utilization of Antenatal Care Services in India. International Journal Environmental Research in Public Health, 16, 3152. https://doi.org/10.3390/ijerph16173152

[20] Atinga, R.A., Baku, A.A. and Adongo, P.B. (2014) Drivers of Prenatal Care Quality and Uptake of Supervised Delivery Services in Ghana. Annals of Medical and Health Science Research, 4, 264-271. https://doi.org/10.4103/2141-9248.141970

[21] Moller, M., Patten, J., Hansen, C. and Say, L. (2019) Monitoring Maternal and Newborn Health Outcomes Globally: A Brief History of Key Events and Initiatives. Tropical Medicine \& International Health, 24, 1342-1368.

https://doi.org/10.1111/tmi.13313 